\title{
A LEARNING DESIGN FOR ENGAGING ACADEMICS WITH ONLINE PROFESSIONAL DEVELOPMENT MODULES
}

\author{
Iain Doherty \\ Learning Technology Unit, Faculty of Medical and Health Sciences, \\ University of Auckland, New Zealand \\ i.doherty@auckland.ac.nz
}

\begin{abstract}
Our paper describes the design and development of a set of online professional development modules to support academic staff in improving and enhancing their teaching. We show how we created a learning design to allow staff to quickly and easily develop their teaching in line with University performance expectations whilst also providing staff with a sound basis for documenting their professional development using a newly created ePortfolio tool. We present data from the evaluation of the modules and discuss a research project for evaluating the ultimate impact of this initiative on student learning.
\end{abstract}

\section{Keywords}

Learning, design, educational, staff, continuing, professional, development

\section{Introduction}

Our paper describes the design, development and delivery of a set of professional development modules to support academic staff within a Faculty of Medical and Health Sciences in developing their teaching. The modules were created in the context of a broader project to provide staff with a range of teaching supports and resources in line with the Faculty's strategic aim of achieving excellence in teaching. The additional resources included a teaching performance rubric to guide staff in assessing their teaching performance and an ePortfolio to allow academics to maintain teaching records for formative and summative purposes.

From a strategic point of view the performance rubric and the ePortfolio were both considered necessary in order to motivate staff to engage with the professional development modules. From a learning design point of view, the challenge was to develop professional development modules that would allow staff to quickly and easily develop their teaching in line with University performance expectations whilst also providing staff with the means to document their professional development for formative and summative purposes. We will show how we achieved these design aims through underpinning the learning design for the modules with a model of scholarly teaching.

\section{Context}

Continuing Professional Development (CPD) consists of formal and/or informal learning that leads to the enhancement of knowledge, skills and personal attributes necessary to carry out professional duties (Gosha, Billionniere, Gilbert, \& Ramsey, 2010; Guskey, 2000; Stefani, 2005). In this paper, we will refer to CPD for teaching as Educational Professional Development (EPD) (Knight, 2006). EPD is important for the renewal and vitality of the organization the professional development of individual staff members and for improving teaching to enhance and improve student learning (Guskey, 2000; Lanthan, Camblin, \& Steger, 2000). However, longitudinal research into the benefits of EPD has been lacking (Dede, Jass Ketelhut, Whitehouse, Breit, \& 
McCloskey, 2009; Mouza, 2009) and this is something that the Learning Technology Unit at the Faculty of Medical and Health Sciences (http://www.fmhs.auckland.ac.nz/faculty/ltu/) has been addressing in the context of other EPD initiatives (Doherty, 2010; Doherty, Blake, \& Cooper, 2009; Doherty \& Cooper, 2009). We will return to the question of the evaluation of EPD initiatives at the end of our paper.

A range of EPD opportunities are available for academic staff at the University of Auckland. All new teaching staff must take a three-day course - provided by the University's Centre for Academic Development (CAD) - on aspects of teaching at the University. This course is designed to introduce early-career academics to key concepts and strategies for university teaching and learning and to provide a useful refresher course for more experienced teachers. The CAD also offers a Certificate in Academic Practice. This is a credit-bearing program that provides university lecturers with a structured, research-based educational environment in which they can explore theories of tertiary teaching and academic citizenship. Finally, the CAD provides a variety of workshops covering all aspects of university teaching \& supervision including teaching to large classes, effective tutoring, effective assessment practices, use of information technologies in teaching and good practice in postgraduate supervision.

We designed our EPD modules to expand on existing University EPD offerings in two ways. First, we wanted to provide EPD modules with content designed to meet the particular needs of medical and health science educators. For example, clinical educators have to assess student performance in hospital setting and primary health care settings. This requirement is specific to a medical and health sciences educational setting. Secondly, we knew from informal conversations and from an unpublished FMHS staff survey that many staff - and in particular clinical educators - found it difficult to find the time to attend face-to-face workshops. With this in mind we wanted to provide online EPD content that would allow educators to engage in EPD at a time and place of their own choosing.

Our strategy for engaging educators with the EPD modules focused on making a connection with the university promotion processes. In order to realize this strategy we established a project team that included: the Director of the Learning Technology Unit (LTU) in the role of project leader; the Associate Dean Education; the Director of the Centre for Medical and Health Sciences Education (CMHSE); and academic staff members from the LTU and CMHSE. The project deliverables - tangible products resulting from the project - included a teaching performance rubric, the EPD modules and an ePortfolio. The purpose of this paper is to explain the EPD module design process including the integration of the performance rubric and the ePortfolio into the EPD modules. We will, therefore, provide details of the performance rubric in the first instance. We will then describe the design and development of the modules. Finally, we will show how the ePortfolio was integrated into the module learning design.

\section{Performance rubric}

The University of Auckland policy document on academic grades, standards and performance criteria sets out a variety of activities undertaken in the three scholarly domains - teaching, research and service - and provides examples of the sorts of achievements associated with the various performance levels (satisfactory, merit, excellence and distinction). The document is used to aid individual academics in career and promotion planning, to aid academic managers in providing appropriate and consistent advice to potential promotion applicants and to aid staffing committees in making recommendations about promotion. Consideration for promotion to any grade involves two steps. First, the committee must be satisfied that the candidate has reached a satisfactory (or in the case of Associate Professor - merit) level of performance consistent with his or her grade of appointment in each of the three broad areas for promotion. Second, in order to be promoted, the candidate must also demonstrate merit (for promotion to Senior Lecturer), excellence (for promotion to Senior Lecturer over the bar), and distinction (for promotion to Associate Professor), in at least one of the three broad areas. 
We wanted to provide staff with a straightforward way to identify the University's teaching performance expectations and so we decided to create a Faculty representation of the University's teaching performance areas and performance indicators in the form of a teaching performance rubric. An example from the teaching rubric (Table 1 below) will help to make clear how the performance rubric works in practice. Table 1 presents the rubric for one teaching performance area, 'Delivery of teaching to facilitate learning'. Examples of the different sorts of activities that might be evidenced are listed under the four performance levels. We can see, for example, that a satisfactory performance might be evidenced through making use of a range of teaching and learning methodologies. Interested readers can access the full performance rubric at http://www.fmhshub.auckland.ac.nz.

Table 1: Teaching performance areas and associated performance activities

\begin{tabular}{lllll}
\hline & Satisfactory & Merit & Excellence & Distinction \\
\hline $\begin{array}{l}\text { Delivery } \\
\text { of }\end{array}$ & Competent use of & Innovation in & Promotes effective & National / \\
teaching & a range of teaching & teaching & teaching practice at & international \\
to & and learning & methodologies & institutional level & standing in \\
facilitate & engage students in & impact on & peer review, & understanding of \\
learning & the learning & learning. & workshops or & and improving of \\
& process & Applies & seminars. Researches & teaching and \\
& & appropriate & into approaches to & learning. \\
& & pedagogical & teaching that improve & \\
& frameworks to & learning outcomes. & \\
& & & & \\
& & the improvement & & \\
& & practice & & \\
& & &
\end{tabular}

The rubric is not a checklist that dictates that a certain number of specific activities must be demonstrated. Rather the rubric acts as a guide that outlines the kinds of activity that would be regarded as demonstrating performance at a certain level. There is, therefore, room for interpretation when providing examples of particular activities for the various performance levels. For example, staff might demonstrate innovation by introducing and evaluating a new assessment method such as a peer review assessment practice.

\section{Educational professional development modules}

\section{Scholarly teaching}

Once we had produced the teaching performance rubric, we faced two challenges. First, we needed to create a learning design that would connect the EPD module content with the teaching performance rubric. Secondly, we needed to engage staff in a learning process that would lead to evidence based teaching improvement that might be documented in the ePortfolio for formative and summative purposes. We were also guided by another consideration. We wanted to engage educators in a process of scholarly teaching because developing the scholarship of teaching can help to raise the status of teaching relative to discipline research (Boyer, 1990; Healey, 2008; Schroeder, 2007; Trigwell \& Shale, 2004) and because there is some evidence that scholarly teaching provides a solid foundation for developing teaching to improve student learning (Brew \& Ginns, 2008; Spronken-Smith \& Kingham, 2009; Tsang, 2010). The scholarly model of teaching eventually provided us with a solution to the first two design challenges - how to connect the modules with the rubric and the ePortfolio - and we will, therefore, describe the scholarly teaching model in the first instance.

Richlin (Richlin, 2001) provides the model of scholarly teaching (Figure 1 below) that we used in the first stage of our design process. The scholarly teaching process can essentially be divided into 
three distinct steps. Step one involves identifying a teaching a learning challenge and making an informed decision regarding the solution to the challenge. Step two involves implementing a change in teaching practice and recording what happened as a result of the change. Step three consists of evaluating the impact of the intervention. Scholarly teaching is distinguished from the scholarship of teaching in terms of the requirement that scholars of teaching disseminate research findings through peer-reviewed publications. We made the deliberate choice to follow the model of scholarly teaching because the University of Auckland is a research-intensive university with many academics lacking the time and /or inclination to engage in the scholarship of teaching. This situation is not unusual in tertiary institutes of education (Gossman, Haigh, \& Jiao, 2009) and is particularly pronounced in research intensive universities (Asmar, 2002a, 2002b, 2004).

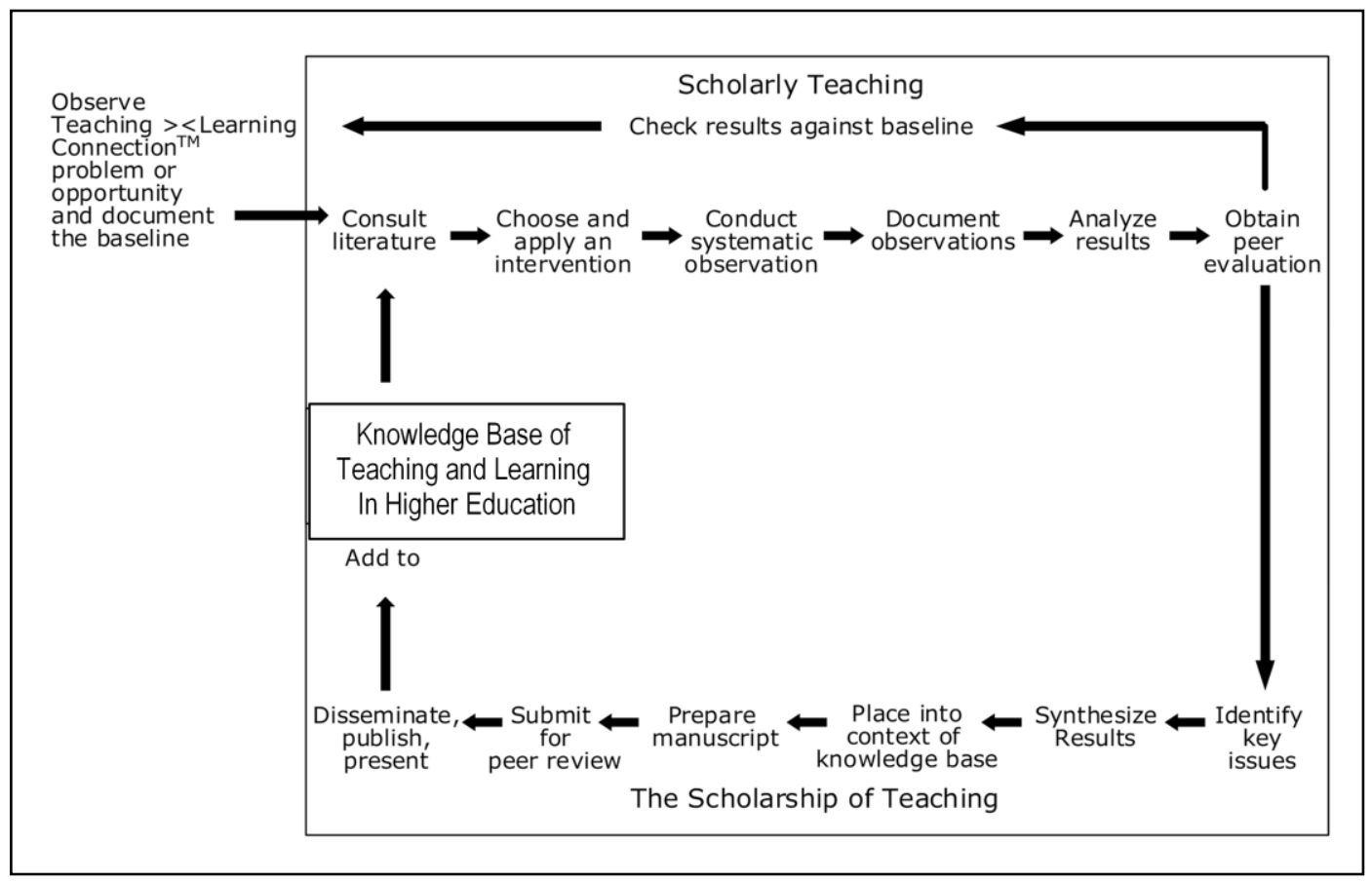

Figure 1: Scholarly teaching

After some consideration we saw that the scholarly teaching steps could be embodied in the EPD learning process in a very straightforward manner. Essentially, educators are guided through step one - identifying a challenge and making an informed choice about a solution - through engaging them with the rubric and the modules. The reason for this is that the rubric specifies performance areas and performance indicators (the challenge) whilst the module content provides research informed solutions to the challenge. Step two - implementation, analysis and documentation - is realized through introducing educators to the ePortfolio within the modules and by directing them to record and analyze the results of their implementation for formative and summative purposes. Finally, step three - evaluating the impact of the change with reference to the original challenge can be achieved through requiring educators to describe what they need to do (next steps) as a result of having implemented a change in their teaching practice.

\section{Module design and development}

Having mapped out our learning design at a broadly conceptual level, we set about creating a more detailed design for the EPD modules. For our purposes EPD extends to the full range of teaching and teaching related activities to be found in a Faculty of Medical and Health Sciences including: delivering lectures; running tutorials; teaching clinical skills; teaching medical and health science 
interns in a clinical setting (e.g. hospital or doctor's surgery); course design; curriculum design; student supervision and pastoral care of students. With the exception of the clinical teaching components, these teaching activities will be common across all institutes of higher education and the content of this paper should, therefore, be relevant to educators in a variety of settings.

We wanted to create a learning design that would engage educators in progressively more demanding levels of cognitive activity appropriate for scholarly teaching. Therefore, we took Anderson and Krathwohl's (Anderson \& Krathwohl, 2001) revision of Bloom's taxonomy (Bloom, 1956) of the cognitive domain in order to represent the different levels of possible learning. Readers may notice that the taxonomy represented in Table 2, differs from the standard representation of Anderson and Krathwohl's taxonomy. In the usual representation the order is as follows: knowledge; comprehension; application; analysis; synthesis (create / build); and evaluation. In our representation analysis and synthesis (designing a teaching intervention) precede application and evaluation (teaching practice and ePortfolio records). The reason for our revised representation is that we wanted an order for the levels of the cognitive domain in which the learners - in this case, teachers - engage in progressively deeper levels of learning mapped to the scholarly teaching model already outlined.

Table 2: The act of learning

\begin{tabular}{ll}
\hline The Act of Learning & Bloom's Taxonomy \\
\hline \multirow{2}{*}{ Acquisition [New knowledge] } & Knowledge [Recalling facts] \\
& Comprehension [Constructing new meaning] \\
Transformation [Application of & Analysis [Subdividing and contrasting) \\
knowledge] & Synthesis [Reorganizing elements] \\
& Application [Relating learning to new situation] \\
Evaluation [Determining utility] & Evaluation [Determining potential utility] \\
\hline
\end{tabular}

Based on the initial design work outlined above, we wrote a series of intended learning outcomes for the EPD modules. The outcomes addressed each of the teaching performance areas found in the teaching performance rubric. We then structured the module content to scaffold educators (Scardamalia, et al., 1992; Scardamalia, Bereiter, Swallow, \& Woodruff, 1989; Vygotsky, 1978) through a series of reflective activities that culminated in asking teachers to start an ePortfolio record to baseline the teaching challenge/opportunity (Richlin, 2001) that they had identified as a result of their engagement with the EPD modules. This represents the last learning step in the module and the first step in creating an ePortfolio record. We then used a custom course creation tool to create basic content for the first two modules. The content consisted of text, images, and links to additional research resources (journal articles and websites) for those educators wanting to take their learning further.

\section{Development}

We showed the two draft modules to 6 educators - from the level of tutor through to professor and asked for feedback in the following areas: buy in/use of the teaching modules by FMHS academic staff and clinical teachers; design and layout of the modules; important/desirable content. We received the unanimous response that academics did not like the modular approach that we had taken. This response from one of the interviewees captures the sentiment.

Don't give staff modules - don't make it feel like hard work. Tell us what can be done.

One respondent indicated that it would be most useful to be able to access information based on specific questions that teachers ask when they teach. Based on an indication in the literature that professional learning tends to be informal and practice based (Knight, 2006), we picked up on this 
suggestion and decided to present the content in terms of a series of questions and related answers categorized under the different teaching performance areas in the teaching and learning rubric. This strategy provided for just in time online learning (Gosha, et al., 2010) connected with what academics do in their teaching. The module structure can be seen in the navigation menu on the left hand side of Figure 2 below where one of the modules - 'Delivery of teaching to facilitate learning' - has been expanded to reveal the questions. The questions relate both to teaching practice and to the sorts of activities that might be used to evidence teaching performance. For example the question, 'How can I engage my students in learning?' is the sort of question that might be asked in teaching whilst the answer to the question provides educators with the information that they need to evidence satisfactory performance in the 'Delivery of teaching to facilitate learning.'

\begin{tabular}{l} 
Home \\
\hline Delivery of teaching to \\
facilitate learning \\
What makes a good \\
teacher? \\
How do I plan my \\
teaching? \\
How can I engage my \\
students in learning? \\
What is the best \\
teaching approach? \\
When should I use \\
technologies? \\
How do I evaluate the \\
impact of an \\
innovation? \\
\hline Design and planning of \\
courses/programmes \\
\hline Assessing learning \& \\
providing feedback \\
\hline Addressing diversity \\
\hline Evaluation of practice \\
and continuing \\
professional \\
development \\
\hline Contribution of \\
scholarship, research \\
\& professional \\
activities to teaching \& \\
learning \\
\hline Student Support, \\
Guidance and \\
Supervision \\
\hline
\end{tabular}

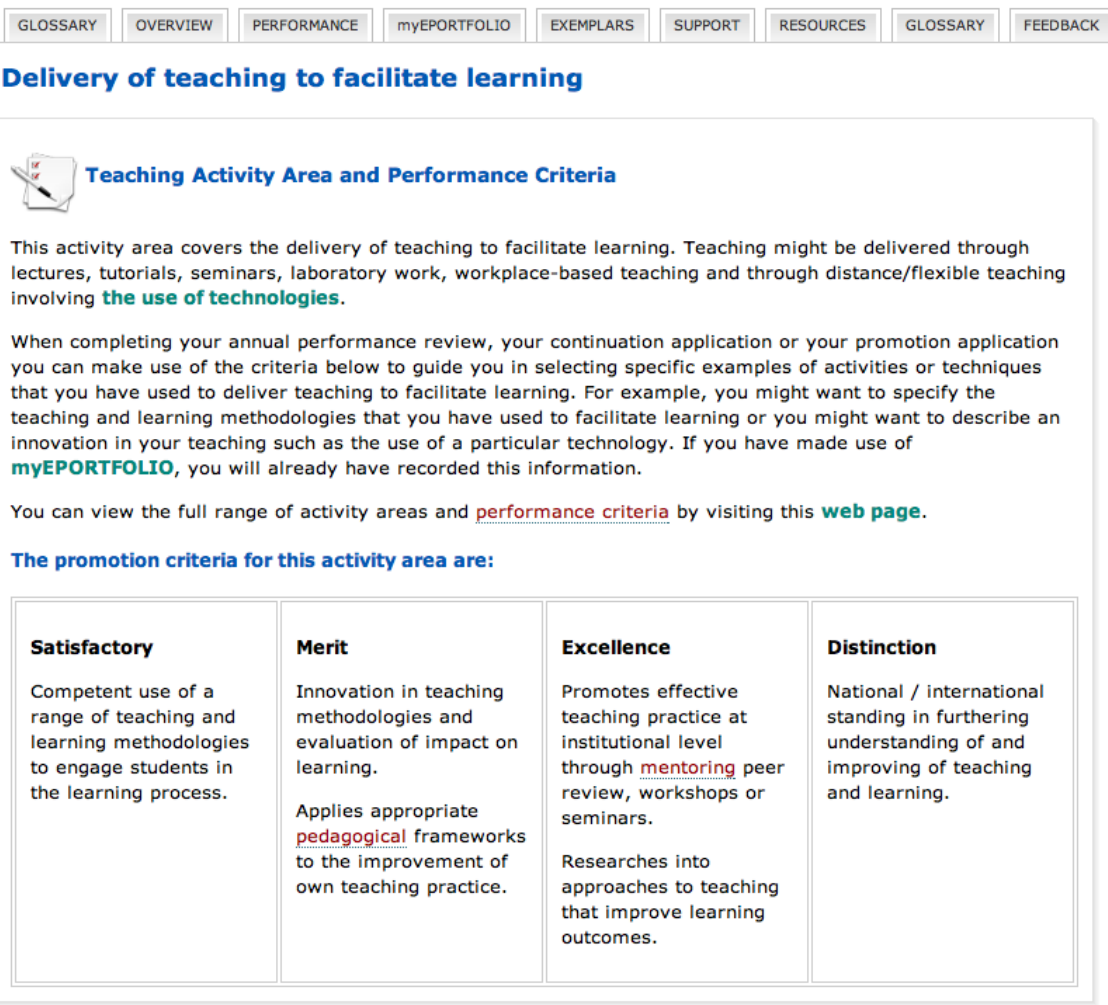

Figure 2: Teaching performance area and performance activities (screen capture)

We also removed the learning outcomes from the modules because these defined the EPD modules as a course that had to be worked through. Rather than creating content / learning activities around learning outcomes, we structured each module to scaffold learners through a series of reflective tasks that involved progressively deeper levels of learning culminating in learners designing (synthesis in the learning taxonomy) a teaching intervention that would meet their identified teaching challenge. For example, in the section on 'What makes a good teacher?' educators are presented with some basic information on good teaching. This is followed by three videos of wellknown university educators talking about what makes a good teacher. Users are then asked to complete a teaching perspective inventory to give them insight into the way in which they approach their teaching. This is followed by information on a teaching philosophy. Users are then asked to write their own teaching philosophy. Finally, we suggest that users start an ePortfolio record and that they write their own teaching philosophy. The learning activities in this - and other modules - reflects EPD research suggesting that EPD activities must engage learners in real world learning that has direct relevance to their teaching (Bell \& Morris, 2009; Mouza, 2009; 
Samarawickrema, Benson, \& Brack, 2010; Stefani, 2002). The learning structure also progresses users through the levels of the cognitive domain outlined above.

Interviewees made particular mention of wanting to know more about teaching with technologies. Given the university's commitment to enhancing teaching through the use of technologies, we included a specific section on technology use under the performance area of 'Delivery of teaching to facilitate learning'. Interviewees also suggested the use of short informative video clips of wellknown educators within the Faculty / University. We recorded FMHS and University teaching and learning "personalities" talking about particular aspects of teaching and learning. The videos that we produced included various educators talking about what makes a good teacher (see above), the winner of the Faculty's 2009 award for $\mathrm{PhD}$ supervision talking about excellence in supervision and recipients of various Faculty and University teaching awards talking about teaching activities such as delivering teaching to facilitate learning and engaging students in learning. Finally, interviewees also requested best practice examples. With this suggestion in mind we created an exemplar page with best practice teaching examples from across the Faculty.

\section{Evaluation}

We asked $5(\mathrm{~N}=5)$ academics to review the beta version of the modules. Their positions in the Faculty were as follows: Senior Tutor (2); Lecturer (1); Associate Professor (2). The broad purpose of the evaluation was to gather feedback on the content of the site and to assess site design / usability.

We asked, "How well do you think the web site meets the teaching and learning development needs of the Faculty?" and participants could respond on a five point Likert scale that ranged from "Very Well" to "Not Well At All." 4 (n=4) participants responded, "Very Well" and 1 (n=1) participant responded with "Well." Participants were also given the opportunity to explain their responses. These responses are representative.

Content is linked explicitly to University and faculty performance criteria. This could be stifling, but it isn't. The material is well summarized, clear and practical. The 'talking heads' videos are, in the main, engaging and complementary.

It looks comprehensive and very user friendly. It also provides easy access to relevant resources. I particularly like the three progression steps e.g. taking if further $\&$ link to eportfolio.

We asked, "Will you make use of this website for your professional development?" and respondents could answer, "Yes", "No" or "Maybe." $4(n=4)$ participants responded with "Yes" and $1(\mathrm{n}=1)$ participant responded with, "Maybe." The respondent who answered "Maybe" was a senior member of Faculty who qualified the response by explaining that the content of the site was better suited to those with less teaching experience. Additional comments on whether they would make use of the site for their own professional development included:

Most likely I'd recommend it to other staff starting out in teaching or staff needing to generate information for promotion.

Because it refers explicitly to promotion criteria.

We asked, "How valuable/useful do you think this website is for supporting you in your own professional development?" and participants could respond on a five point Likert scale from "Very Useful" to "Not Useful At All." 2 (n=2) participants responded with, "Very Useful", 2 (n=2) with "Useful" and $1(\mathrm{n}=1)$ with "Quite Useful." The respondent who answered "Quite Useful" was the same senior member of Faculty who felt that the content was better suited to those with less 
teaching experience. Comments from academics on the perceived usefulness of the site for their own professional development included:

The level is well pitched. It would allow a novice teacher to get started and provides something to stretch more experienced teachers.

This is perfect timing, as I need to apply for a promotion this year. As my role in the University does not have a research commitment I often think that it is difficult to reflect my value and contribution to this organization but this website provides good scaffolding to let me highlight strengths and innovation.

The comment concerning timing and promotion came from a Senior Tutor, a position that does not require research on the part of the appointee. Teaching performance is, therefore, very important in a promotion application.

Finally, we asked "Would you recommend this website to other educators?" and participants could respond with "Yes", "No" or "Maybe." All $5(\mathrm{n}=5)$ participants responded with "Yes". There was only 1 comment for this question.

In process of employing new tutor/lecturer and will definitely point them in this direction.

We asked, "How visually appealing is the web site?" and participants could respond on five point Likert scale from "Very Appealing" to "Not Appealing At All." 3 (n=3) participants responded with "Very Appealing" and $2(\mathrm{n}=2)$ participants responded with "Appealing."

Comments on visual appeal were wholly positive with this comment being representative.

The layout is attractive without being dominant. Some sites are great to look at and navigate, but underwhelming in content and application. The design isn't 'fussy'. I like the tab structure and the uniformity of approach.

We asked, "How easy/difficult is it to navigate the website?" and participants could respond on five point Likert scale from "Very Easy" to "Very Difficult." $4(n=4)$ participants responded with "Very Easy" and $1(\mathrm{n}=1)$ participant responded with "Easy." There was only one comment for this question.

Smooth links to readings and external sites (I found only one broken link - teaching philosophy)

There were no negative comments about site content or site design and as a result of the evaluations we judged that we had produced a resource that was easy to use with appropriate content for the EPD needs of the Faculty. However, we would note that comments from the more senior academic suggest that the content may be more appropriate for "novice" teachers. This judgment is further supported by the comment that the site would be useful for new staff. The fact that the EPD modules appear to be more suitable for new / less experienced teaching staff is not a particular concern because we had made the decision to focus the EPD activities on activities related to the first two performance levels (satisfactory and merit). The reason for making this decision was that the first two performance levels address teaching competencies necessary for excellent teaching. The remaining performance levels (excellence and distinction) address competencies that extend and build upon the core competencies and we took the view that competencies for these levels could be developed both informally through peer support and in other professional development contexts such management and leadership courses. For example, excellence in teaching and learning requires leadership in education at a school / University level and distinction in teaching requires leadership in education at an international level. 


\section{ePortfolio}

From a learning design perspective, the ePortfolio is important because it provides academics with a means to record their EPD activities along with the results of their teaching interventions. A portfolio is a collection of information about teaching practice (Tucker, Stronge, Gareis, \& Beers, 2003). The benefits of maintaining a teaching portfolio include the opportunity to reflect on teaching practice, taking ownership of the need for professional development and having a formal and verifiable record of teaching practice. (Stefani \& Diener, 2005; Tucker, et al., 2003). Portfolios can be maintained for formative and/or summative purposes. At a formative level the portfolio functions as a vehicle for a teacher to maintain an ongoing reflective record of how they are doing in their teaching. At a summative level, a portfolio can be used to evidence teaching performance during reviews, when applying for promotion and when applying for teaching grants or awards for excellence in teaching (Seldin \& Miller, 2009). Teaching portfolios can be maintained as a hard copy or as in an electronic format (ePortfolio). The ePortfolio is perceived to offer distinct practical benefits compared with hard copy portfolios. For example, ePortfolios provide a way for educators to document their teaching and to manage voluminous amounts of portfolio evidence whilst also providing a standardized presentation format for the various reviewers. Online ePortfolios are readily available anywhere and at any time as long as the user has an Internet connection. (Swan, 2009).

We are aware that the use of teaching portfolios is not innovative. Indeed our early research for this project examined the use of teaching portfolios at five Universitas 21 universities: University of Edinburgh; University of Melbourne; University of Queensland; University of British Columbia; and the University of New South Wales. Additionally, there is voluminous literature on teaching portfolios from the United States where teaching portfolios have been recommended for use by in-service teachers, by pre-service teachers and for use by educators in institutes of higher education (Glassick, Huber, \& Maeroff, 1997; Seldin, 1997; Soulier \& Recker, 2001; Swan, 2009; Tucker, et al., 2003). Our research and literature review revealed a number of ePortfolio options ranging from use of off-the-shelf word processing software such as Microsoft Word to create portfolio templates through to custom built ePortfolio systems to provide a feature rich online ePortfolio system.

Having surveyed the options and considered our model of scholarly teaching, we decided to create a customized ePortfolio system that would allow academics to quickly and easily create teaching records aligned with taking a scholarly approach to teaching. We opted for a custom system because we wanted to offer a straightforward online system with additional functionality including a search feature and an upload function for storing associated evidence. Developers at the University's Centre for Academic Development developed the custom ePortfolio system. We consulted with the Faculty Staffing Committee - the committee responsible for making recommendations concerning promotion - and with individual academics during the design process. However, time pressure meant that no formal evaluation was carried out before the release of the ePortfolio. This meant that we had a "soft launch" of the ePortfolio during which we asked academics to use the system over a two-month period and to report back to us on the usefulness of the system.

The form fields (Figure 3 below) for the ePortfolio include: a record description for providing an overview of the portfolio entry (teaching and learning connection); a reflection section for entering details concerning the nature of the teaching challenge / opportunity (baseline activity); an action field for describing what was done (research-based intervention); an evaluation field to present the results of the intervention (analysis of results); and a next steps field for describing follow on actions from the intervention (check results against baseline). The ePortfolio therefore provides a way to record each step in the scholarly teaching process whilst also providing a means for academics to create teaching records suitable for summative purposes including applying for a promotion. Users can also upload evidence of their teaching practice including, for example, electronic student evaluations. The completed record must be printed and appended to university review documentation. This choice to provide a print function to allow academics to generate their 
teaching records was made because we did not have the resources to develop a more complex system that would automatically integrate the teaching records with the various university forms used during formal review processes. Additionally, informal discussions with academics had indicated that academics wanted a very straightforward system.

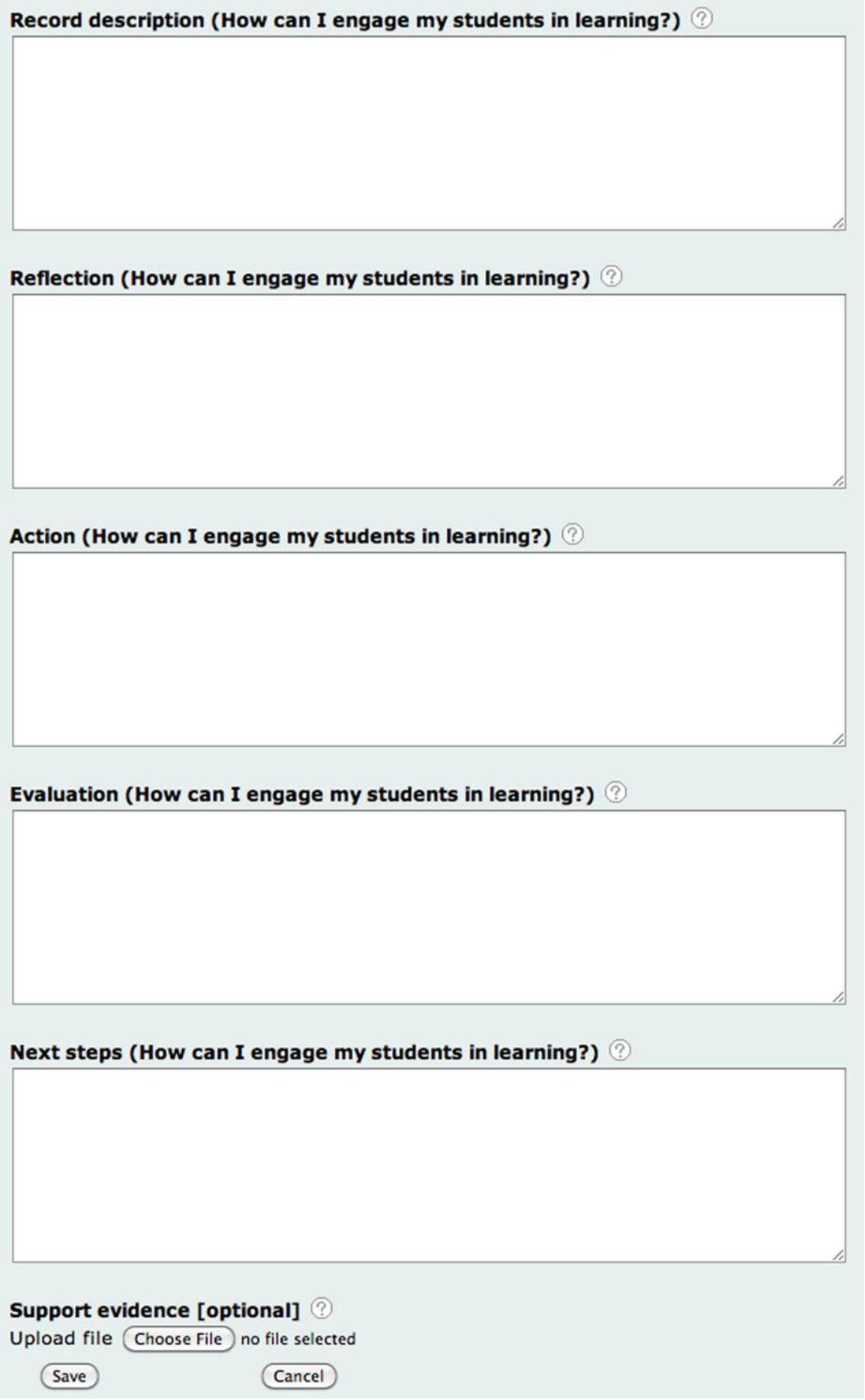

Figure 3: ePortfolio form fields 


\section{Evaluation}

Research to measure the impact of this project might be carried out on a number of different levels including: the usefulness of the modules for teaching staff; the usefulness of the teaching and learning rubric for teaching staff, academic managers and members of the staffing committees; and the usefulness of the ePortfolio for teaching staff, academic managers and the members of the staffing committees. Each of these evaluation levels is important from a strategic point of view, particularly in terms of determining the degree of systemic change within the Faculty. However, the core purpose of EPD is to make teaching both more rewarding and more effective (Lanthan, et al., 2000) and systemic change per se means very little unless teaching does actually become more rewarding and more effective.

At the time of writing we are developing a research project to evaluate the impact of this project at a systemic level. We also want to evaluate teacher development and impact on student learning. With the question of systemic change in mind, we will be evaluating: use and perceived value of the teaching modules (all teaching staff); use and perceived value of the electronic teaching portfolio (teaching staff, academic managers and members of the staffing committee); and use and perceived value of the teaching guidelines (teaching staff, academic managers and members of the staffing committee). We are still in the process of creating the questionnaires. However, we can give some indication of the evaluation specifics. The EPD module questionnaire will ask questions about the user experience of the EPD modules - navigation, design, structure and clarity of presentation - and about degree of engagement with the EPD content. For example, we are intending to ask about the extent to which teachers engaged with the research base for the modules, the extent of independent research into teaching practice and about any changes that teachers made to their teaching as a result of engaging with the modules. The performance framework questionnaire will ask the three groups about the extent to which they made use of the framework and about the perceived value of the framework in their particular contexts. For example, we will ask the Staffing Committee whether they found the framework useful when making recommendations about promotion applications. The ePortfolio questionnaire will ask the three groups about the extent to which they made use of the ePortfolio and about the perceived value of the ePortfolio in their particular contexts. For example, we will ask academic managers whether they judged any teaching portfolios prior to a staff member making an application for promotion.

Thomas Guskey (Guskey, 2000) draws on a number of evaluation models - including the well known Kirkpatrick model - to describe four levels of evaluation that are important if we want to measure whether teaching has become more rewarding and more effective as a result of EPD. These levels are: participants' reactions to the EPD; whether or not participants achieved the desired learning outcomes; participants' use of new knowledge and skills in their teaching; and resultant improvements in student learning. Our current evaluation plan focuses on participants' use of new knowledge and skills (the EPD questionnaire) and on resultant improvements in student learning (the ePortfolio questionnaire). For example, the EPD questionnaire asks about changes teachers made to teaching and about their evaluation of the changes that they made. We have more work to do to develop a robust evaluation of the EPD modules. For example, Guskey (Guskey, 2000) makes the point that it is important to evaluate the user experience along with whether or not participants achieved the desired learning outcomes because a positive experience along with achieving learning outcomes are both necessary conditions for making effective changes to teaching practice. The work of Reeves and Hedberg on evaluating interactive learning systems may also prove useful to us (Reeves \& Hedberg, 2003) as we develop our plan for evaluating the EPD modules and we are looking at online evaluation resources provided by Reeves (http://www.evaluateitnow.com/). Finally, we have more work to do to complete the project evaluation plan as a whole and we are currently looking at evaluation resources from the Australian Teaching and Learning Council (ALTC) (http://www.altc.edu.au/extras/altcgsep/index.html) in order to develop our evaluation plan. Work in this area will be completed by 
late September 2010 at which time we will submit an ethics application to the University ethics committee.

\section{Conclusions}

Our paper has described the design and development of a set of EPD modules in the context of a project to achieve systemic change in the teaching culture of a Faculty of Medical and Health Sciences. We have explained the basis of our learning design and made particular reference to the model of scholarly teaching that underpinned our design decisions. We have presented evaluation data for the modules along with data reporting participants' reactions to the pre-release version of the EPD modules. We have also shown how the ePortfolio played an integral part in the design and development of the EPD modules through providing the means for teachers to record their professional development for formative and summative purposes. Finally, we discussed our evaluation plan in some detail and indicated that we still have work to do in order to develop a robust evaluation framework. The EPD modules and the ePortfolio were launched in late April 2010. The challenge now is to promote and embed these resources in the teaching culture of the Faculty. Work has already begun in this area and we hope to report on this process in $2011 / 2012$. We will also be reporting on the results of our evaluations in $2011 / 2012$.

\section{References}

Anderson, L. W., \& Krathwohl, D. R. (Eds.). (2001). A Taxonomy for Learning, Teaching, and Assessing: A Revision of Bloom's Taxonomy of Educational Objectives. New York: Longman.

Asmar, C. (2002a). Strategies to Enhance Learning and Teaching in a Research Intensive University. International Journal for Academic Development, 7(1), 18-29.

Asmar, C. (2002b). Turning Academics into Teachers, and Teachers into Scholars: Approaches to Scholarship at a Research-Extensive University. Paper presented at the 4th World Conference of the International Consortium for Educational Development, Perth, WA.

Asmar, C. (2004). Innovations in Scholarship at a Student-Centered Research University: An Australian Example. Innovative Higher Education, 29(1), 18-29.

Bell, A., \& Morris, G. (2009). Engaging Professional Learning in Online Environments. Australasian Journal of Educational Technology, 25(5), 700-713. Retrieved from http://www.ascilite.org.au/ajet/ajet25/bell.pdf

Bloom, B. S. (1956). Taxonomy of Educational Objectives: Handbook I - the Cognitive Domain. New York: Longman.

Boyer, E. L. (1990). Scholarship Reconsidered: Priorities of the Professoriate. Princeton: Carnegie Foundation for the Advancement of Teaching, Princeton, NJ.

Brew, A., \& Ginns, P. (2008). The Relationship between Engagement in the Scholarship of Teaching and Learning and Students' Course Experiences. Assessment \& Evaluation in Higher Education, 33(5), 535 - 545.

Dede, C., Jass Ketelhut, D., Whitehouse, P., Breit, L., \& McCloskey, E. M. (2009). A Research Agenda for Online Teacher Professional Development. Journal of Teacher Education, 60(1), 8-19.

Doherty, I. (2010). Staff Development Workshops for Teaching with Web 2.0 Tools. In C. D. Maddux, D. Gibson \& B. Dodge (Eds.), Research Highlights in Information Technology and Teacher Education 2010 (pp. 61-70). Chesapeake, V.A: SITE.

Doherty, I., Blake, A., \& Cooper, P. (2009). Staff Development Workshops: Web 2.0 for Teaching and Learning. Paper presented at the Society for Information Technology and Teacher Education 20th International Conference, Charleston, South Carolina, USA. 
Doherty, I., \& Cooper, P. (2009). Educating Educators in the Purposeful Use of Web 2.0 Tools for Teaching and Learning. Paper presented at the ascilite 2009 conference, Auckland, New Zealand.

Glassick, C. E., Huber, M. T., \& Maeroff, G. I. (1997). Scholarship Assessed: Evaluation of the Professoriate. San Francisco: Jossey-Bass.

Gosha, K., Billionniere, E., Gilbert, J., \& Ramsey, M. (2010). Developing a Framework for Teacher Professional Development Using Online Social Networks. Paper presented at the Society for Information Technology \& Teacher Education International Conference (SITE) 2010, San Diego, CA.

Gossman, P., Haigh, N., \& Jiao, X. (2009). The Status of the Scholarship of Teaching and Learning (SoTL) in Three New Zealand Universities: Three Instituational Case Studies (Final Report). New Zealand.

Guskey, T. R. (2000). Evaluating Professional Development. Thousand Oaks, California: Corwin Press Inc.

Healey, M. (2008). Discipline-Based Approaches to SoTL. The International Commons, 3(1), 2-3. Retrieved from http://www.issotl.org/newsletter.html

Knight, P. (2006). Quality Enhancement and Educational Professional Development. Quality in Higher Education, 12(1), 29-40.

Lanthan, D., Camblin, J. R., \& Steger, J. A. (2000). Rethining Faculty Development. Higher Education, 39, 1-18.

Mouza, C. (2009). Does Research-Based Professional Development Make a Difference? A Longitudinal Investigation of Teacher Learning in Technology Integration. Teachers College Record 3(5), 1195-1241.

Reeves, T. C., \& Hedberg, J.G. (2003). Interactive Learning Systems Evaluation. Englewood Cliffs, New Jersey: Educational Technology Publications.

Richlin, L. (2001). Scholarly Teaching and the Scholarship of Teaching. In L. Richlin (Ed.), New Directions for Teaching and Learning (Vol. 86, pp. 57-68). Brisbane, Australia: John Wiley \& Sons, Inc.

Samarawickrema, G., Benson, R., \& Brack, C. (2010). Different Spaces: Staff Development for Web 2.0. Australasian Journal of Educational Technology, 26(1), 44-49.

Scardamalia, M., Bereiter, C., Brett, C., Burtis, P. J., Calhoun, C., \& Lea, N. S. (1992). Educational Applications of a Networked Communal Database. Interactive Learning Environments, 2(1), 45 - 71.

Scardamalia, M., Bereiter, R. S., Swallow, M. J., \& Woodruff, E. (1989). Computer Supported Intentional Learning Environments. Journal of Educational Computing Research, 5(1), 51-68.

Schroeder, C. M. (2007). Countering SoTL Marginalisation: A Model for Integrating SoTL with Instituational Initiatives. International Journal for the Scholarship of Teaching and Learning, 1(1), 1-9.

Seldin, P. (1997). The Teaching Portfolio. In R. Edgerton, P. Hutchings \& K. Quinlan (Eds.), A Practical Guide to Improved Performance and Promtion / Tenure Decisions. Bolton, MA: Anker Publishing.

Seldin, P., \& Miller, J. E. (2009). The Academic Portfolio. San Francisco: Jossey Bass.

Soulier, S., \& Recker, M. (2001). Development of an Eportfolio Builder for Teacher Education. Paper presented at the Society for Information Technology \& Teacher Education International Conference 2001, Norfolk, VA.

Spronken-Smith, R., \& Kingham, S. (2009). Strengthening Teaching and Research Links: The Case of a Pollution Exposure Project. Journal fo Geography in Higher Education, 33(2), 241-253.

Stefani, L. (2002). Continuing Professional Development of Academic Teachers through Self Initiated Learning. Assesment \& Evaluation in Higher Education, 27(2), 117-129.

Stefani, L. (2005). PDP / CPD and E-Portfolios: Rising to the Challenge of Modelling Good Practice. Paper presented at the Reflective Learning, Future Thinking: ALT Spring Conference and Research Seminar. Retrieved from http://www.alt.ac.uk/docs/lorraine_stefani_paper.doc 
Stefani, L., \& Diener, S. (2005). The E-Portfolio as a Tool for Professional Development. Paper presented at the Educause Australasia Conference: The Next Wave of Collaboration. Retrieved from www.caudit.edu.au/educauseaustralasia/2005/PDF/A9.pdf

Swan, G. (2009). Examining Barriers in Faculty Adoption of an E-Portfolio System. Australian Journal of Educational Technology, 25(5), 627-644. Retrieved from http://www.ascilite.org.au/ajet/ajet25/swan.pdf

Trigwell, K., \& Shale, S. (2004). Student Learning and the Scholarship of University Teaching. Studies in Higher Education, 29(4), 523-536.

Tsang, A. (2010). The Evolving Professional (Ep) Concept as a Framework for the Scholarship of Teaching and Learning. International Journal for the Scholarship of Teaching and Learning, 4(1). Retrieved from http://academics.georgiasouthern.edu/ijsotl/v3n2/personal_reflections/PDFs/Reflection_T sang.pdf

Tucker, P. D., Stronge, J. H., Gareis, C. R., \& Beers, C. S. (2003). The Efficacy of Portfolios for Teacher Evaluation and Professional Development: Do They Make a Difference? Educational Administration Quarterly, 39(5), 572-602. Retrieved from http://dx.doi.org/10.1177/0013161X03257304

Vygotsky, L. S. (1978). Mind in Society. Cambridge, MA: Harvard University Press.

Copyright @ 2010 lain Doherty 